\title{
A GESTÃO COLETIVA DOS SERVIÇOS DE SAÚDE PÚBLICA: UMA PERSPECTIVA ERGOLÓGICA
}

\author{
THE COLECTIVE MANAGEMENT OF PUBLIC HEALTH SERVICES: AN ERGOLOGICAL PERSPECTIVE
}

\author{
Maristela Botelho França ${ }^{1}$ \\ Hélder Pordeus Muniz ${ }^{2}$
}

Resumo A partir da análise de situações de trabalho, observa-se que a gestão do trabalho não é responsabilidade do indivíduo, mas das entidades coletivas relativamente pertinentes. São elas que possibilitam as renormatizações, construindo negociações de modo que as renormatizações não ocorram em um movimento individualista, mas na sinergia da construção de um patrimônio histórico. São retomadas reflexões realizadas em dois serviços de um hospital público no Brasil e, com uma perspectiva ergológica, discutese que essas entidades coletivas não são previamente estabelecidas, pois emergem do debate de normas e de valores que acontecem no desenvolver das atividades. No serviço de marcação de exames e no serviço de enfermaria, as normas correspondem simultaneamente a normas relativas aos procedimentos e à organização do trabalho, mas também dizem respeito ao tratamento singular de situações específicas dos pacientes que colocam em debate valores sem escala de medida (do bem comum) e valores mensuráveis (mercantis). $\mathrm{O}$ processo que se dá tem consequência tanto para o trabalho de gerentes e trabalhadores dos serviços quanto para o do interventor-ergologista, para os quais compreender melhor em conjunto a inter-relação entre esses valores e como melhor trabalhar com eles no processo de gestão torna-se uma tarefa primordial.

Palavras-chave trabalho em saúde; gestão; entidades coletivas relativamente pertinentes; debate de valores; perspectiva ergológica.
Abstract From the analysis of work situations, it is observed that the management of work is not the responsibility of the individual but of relatively pertinent collective entities. They are what enable the renormalizations, building talks so that the renormalizations do not occur in an individualistic movement, but in the synergy of the construction of a historical heritage. Reflexions concerning two services of a public hospital in Brazil are retaken and, with an ergological perspective, it is discussed that these collective entities are not predetermined, as they emerge from the debates of norms and values that occur in developing activities. In the service of marking of exams and the ward service, the norms correspond simultaneously to norms related to procedures and organization of work, but they also correspond to the singular treatment of specific situations of the patients who pose a debate without measurement scale (the common good) and measurable values (market). The process that happens has consequences in the work of managers and workers of the services, and also the work of the intervener-ergologist, for whom it's a primary task to better understand collectively the interrelationship of these values and how to better work with them in the management process.

Keywords health work; management; relatively pertinent collective entity; values debate; ergological perspective. 
Os serviços de saúde pública no Brasil têm sido alvo de diversas críticas por parte dos usuários e dos próprios profissionais, o que gerou, inclusive, iniciativas governamentais como a Política de Humanização dos Serviços de Saúde. No Brasil, entre os diferentes estudos acadêmicos que tentam analisar e intervir nas situações de trabalho nesses serviços, vem se desenvolvendo um certo conjunto de pesquisas baseadas na perspectiva ergológica (Schwartz, 2000), que coloca a atividade e a gestão do 'corpo-si' na mira do olhar e da ação transformadora (Muniz, 2000; França, 2002; Joazeiro, 2002, 2008; Scherer, 2006; Silva, 2006; Santorum, 2006; Masson, 2007; Villa, 2008; Souza, 2009; Monteiro da Silva, 2008; Hennington, 2008; Gomes, 2009; Ramminger, 2009).

No presente artigo, vamos retomar alguns resultados das pesquisas que fundamentaram as nossas teses de doutorado (Muniz, 2000; França, 2002) a partir de situações de trabalho em saúde, com o objetivo de discutir pressupostos teóricos que nessas pesquisas, na época, não foram suficientemente desenvolvidos, os quais Schwartz (2009a, 2009b, 2010a) tem explicitado com uma maior clareza em trabalhos mais recentes. Assim, trata-se de, dez anos depois de encerrada as pesquisas/intervenções sobre a gestão do trabalho realizada no serviço de internação de pacientes de neurocirurgia e no guichê de marcação de exame radiológico de um hospital universitário público do município do Rio de Janeiro, colocar em debate alguns aportes que a adoção de uma perspectiva ergológica traz para a compreensão/transformação dessas situações de trabalho em saúde. O principal ponto comum retirado das situações estudadas, escolhido como foco deste artigo, é a importância para a 'gestão' do trabalho em saúde da observância das ECRPs e a sua articulação com um debate de normas e valores. Visamos a demonstrar que esse debate de normas em um mundo de valores tem consequência para a vida no trabalho e no entendimento de eficácia. Consequência tanto para o trabalho de gerentes e de trabalhadores dos serviços quanto para o do interventor-ergologista, para os quais compreender melhor a inter-relação entre esses valores e como melhor trabalhar com eles no processo de gestão precisa ser uma tarefa em comum.

\section{Perspectiva epistemológica e abordagem teórica}

\section{Um estudo em colaboração}

Sendo fiéis ao projeto de compreender o presente pelo passado e o passado pelo presente, com o intuito de situar as problemáticas associadas à gestão do trabalho em saúde, visamos a colocar 'a atividade em história' propondo um quadro específico do contexto sócio-histórico da intervenção realizada. 
A última década do século XX marcou a história brasileira e mundial como um período de mudanças radicais na estrutura das sociedades. Engendradas pelas esferas político-econômicas dominantes, essas mudanças são apontadas por aqueles que as defendem como essenciais não só para se reter a crise econômica como também para que se possa caminhar no ritmo dos 'avanços' 3 tecnológicos. Na verdade, isso vai significar para os críticos do que foi denominado neoliberalismo uma estratégia do capital em nível mundial para fazer a regulação das crises do capitalismo, com a adoção de estratégias que visam ao enfraquecimento dos movimentos dos trabalhadores e outros movimentos sociais, bem como a destruição dos direitos sociais básicos (Antunes, 2007) conquistados pelos mesmos que afirmavam valores do bem comum, como saúde, educação e segurança para todos.

Visando a diminuir o papel do Estado na administração econômica e social do país, empresas e serviços são privatizados, diminuem-se os montantes das verbas destinadas ao gasto público e se aumentam as formas de controle de gestão das finanças. O âmbito dos serviços públicos de saúde no Brasil não representa exceção, havendo redução e corte de verbas, implementação de programa de incentivo à demissão do efetivo, uma diminuição dos concursos públicos e achatamento salarial e a utilização da contratação de temporários para diminuir os impactos da falta de trabalhadores em funções essenciais.

Nesse cenário, dirigentes de hospitais públicos são pressionados a encontrar formas de adaptar os serviços prestados a uma utilização ainda mais racional e parcimoniosa dos recursos econômicos disponíveis, cada vez menos garantidos. No que se refere ao Hospital Clementino Fraga Filho (HU), da Universidade Federal do Rio de Janeiro (UFRJ), a estratégia para lidar com as novas exigências inclui a contratação de uma ação ergonômica em sua qualidade de prática voltada para o estudo de situações de trabalho singulares e socialmente situadas, tendo como objetivo a compreensão da atividade e a transformação da situação profissional. O parceiro técnico escolhido foi o Grupo de Ergonomia e Novas Tecnologias (Gente), coordenado pelo professor Mario Cesar Vidal, vinculado naquele momento à área de engenharia do produto e de gerência de produção da Coordenação de Pesquisa e Pós-Graduação em Engenharia (Coppe/UFRJ).

\section{Um ponto de partida: ergonomia situada}

Por sua natureza complexa, a atividade de trabalho é objeto de estudo que deve ser abordado em etapas articuladas, razão pela qual a metodologia da análise ergonômica é uma escolha fecunda para quem se propõe a responder a diversas demandas relativas à compreensão e melhoria de processos de trabalho. As ações ergonômicas que o grupo Gente realiza desde 1991 
centralizam-se no papel que os coletivos humanos exercem no sucesso/insucesso da modernização de processos de trabalho em indústrias de processamento contínuo, na agricultura e nas organizações de serviços (Vidal, 1997).

No caso do HU, a demanda verbalizada pela direção veio ao encontro de uma proposta específica do Gente: alargar a competência coletiva referente às atividades de serviços hospitalares com relação à prática de uma ergonomia que, partindo da análise ergonômica do trabalho e passando pela construção de modelos de funcionamento, pudesse chegar à concepção de ferramentas de assistência ao trabalho (Vidal, 1997). Assim, é criado um novo ramo de atuação do grupo, especificamente para atender à demanda do HU, por intermédio do Programa de Capacitação em Ergonomia Hospitalar (Proceh) (Vidal et al., 1997).

Para essa primeira ação no âmbito do Proceh, constituiu-se um coletivo de pesquisa formado por seis pós-graduandos - mestrandos e doutorandos - em engenharia de produção, na linha da ergonomia conduzida pelo Gente, entre eles três psicólogos, dois engenheiros e uma designer, somando-se, um pouco mais tarde, uma linguista com a finalidade de, a partir da analise ergonômica do trabalho, explorar também aquilo que o patrimônio de saberes acumulados sobre a linguagem (de Bakhtin e Vygotsky a Schwartz, Faïta e Clot) pode contribuir para o desdobramento de encontros sobre o trabalho.

A reflexão que fazemos neste texto tira seus elementos da parte dessa intervenção realizada por um psicólogo no serviço de internação de pacientes de neurocirurgia (Muniz, 2000) e por uma linguista no serviço de marcação de exames radiológicos (França, 2002) no contexto de uma pesquisaintervenção. Portanto, parte da análise ergonômica do trabalho se desdobra em uma perspectiva ergológica do trabalho em hospital. O principal aporte dessa perspectiva, escolhido como foco neste artigo, é a importância para a gestão do trabalho em saúde de uma compreensão de que a eficácia se constrói pela dinâmica das ações empreendidas por ECRPs em sua articulação com os debates de normas e com o mundo dos valores mercantis e sem dimensão (Schwartz, 2009b).

\section{A perspectiva ergológica: construindo os fundamentos}

A reflexão de Schwartz (1997) sobre os processos ergológicos se orienta inicialmente por compartilhar a perplexidade da equipe participante do dispositivo Análise Pluridisciplinar de Situações de Trabalho (APST), do departamento de ergologia da Universidade de Provence, suscitada por anos de investigação coletiva sobre o campo usualmente qualificado 'trabalho'.

Para o filósofo, falar da atividade laboral "significa se expor a todas as espécies de encontros frequentemente inesperados, quando se crê perder o fio de sua preocupação inicial" (Schwartz, 1997, p. 1). Significa também, 
continua Schwartz, levar a se perguntar sobre como se ligam o corpo e o psiquismo, como se articulam o privado e o público, o cálculo de mercado e os valores que não têm escala de medida, o industrioso, o ético e o político.

Dado o fato de que a palavra trabalho é utilizada para cobrir vários domínios, como os da experiência, de definições, "de valências efêmeras ao mesmo tempo sincrônicas e diacrônicas" (Schwartz, 1997, p. 4), o problema inicial para um pesquisador diz respeito exatamente a essa dificuldade de circunscrever um objeto estabilizado 'trabalho'. Definir trabalho só é possível se resultar em um sentido estrito, relativo a uma forma histórica específica da atividade humana. Assim, sob uma perspectiva parcial de nossa época, o trabalho pode ser definido como uma atividade remunerada segundo valores de mercado. Esse plano de definição serviria apenas para opor trabalho escravo a trabalho não escravo, por exemplo.

A razão da dificuldade de se definir 'trabalho' reside no fato de que, concretamente, ele existe sob a forma de atividades e ações de sujeitos no desenrolar de sua história. Considerando que as atividades sempre em parte singularizam uma situação, Schwartz propõe focalizá-las no interior de processos ergológicos, o que implica balizar três importantes questões epistemológicas: 1) como lidar com o problema dos conceitos que ambicionam neutralizar as variáveis tempo e lugar desses processos; 2) como vencer a dificuldade de fazer uso dos conceitos sem cair numa 'conceituomania' improdutiva; 3) que precauções tomar contra a possibilidade que se apresenta para um conceito de representar um único ponto de vista.

Desse questionamento se depreende que pesquisar e intervir no meio das atividades de trabalho não são tarefas simples. Entretanto, Schwartz (1997) aposta que se pode, a partir de uma perspectiva ergológica, transformar positivamente a questão sobre como se colocar em face do trabalho. Propõe um caminho que leva a observar o conhecimento sobre o trabalho a partir de tendências, sob a perspectiva de um espaço epistemológico descrito como um dispositivo que coloca em dinâmica três polos: 1) das disciplinas, de onde parte a necessidade de se lidar com conceitos ligados a diferentes disciplinas; 2) das forças de convocação e de validação (Schwartz, 2010b), de onde partem a experiência dos trabalhadores, seus saberes investidos nas ações e suas respostas singulares e coletivas construídas frente às convocações de si que lhes faz o trabalho; 3) da disciplina ergológica, de onde partem as exigências epistemológicas e éticas na produção de conhecimento sobre o trabalho com valores e conceitos.

O trabalho de investigação em si situa-se no campo da disciplina ergológica e está inserido na história. Por exemplo, as investigações que originaram este texto aconteceram em um determinado período durante um processo de doutoramento. Porém, as situações de trabalho situam-se no campo dos processos ergológicos e são 'da história', no sentido de que elas 
são 'a história em desenvolvimento'. Essa dualidade de posições requer vigilância epistemológica e ética como parte das exigências ergológicas.

De um lado, prossegue Schwartz (1997), a disciplina ergológica nas ciências humanas e sociais busca produzir saberes (sobre recepcionistas, médicos e enfermeiras, a respeito de sua atividade linguageira dialógica, da economia da saúde, das controvérsias) e manipula conceitos. De outro, no centro dos processos ergológicos, está o interesse pelo 'resíduo', o elemento da história, essência da atividade humana. O que importa conhecer são coisas 'da' história. Em que medida pode-se, visando a conhecer determinados objetos, neutralizar sua história? A posição epistemológica e ética na perspectiva ergológica resulta em pensar as questões do trabalho colocando em relação dialógica conceitos e experiências. Nessa empreitada, é preciso tomar como parceiros do projeto os protagonistas do trabalho.

\section{Conceitos e valores}

A partir de uma reflexão interligando atividade, valores e conceitos, Schwartz (1997) se vê diante de um desconforto: como não sentir dúvida no modo de abordar aquilo que o microscópio revela como um nó de complexidades? Como se colocar nesse nó? Quem pode dizer como as coisas se passam realmente? E quem pode dizer sobre como as coisas poderiam aí se passar?

É preciso cautela: o estudioso do trabalho deve investigar minuciosamente aquilo que está por trás do próprio mecanismo de produção de conceitos e antecipar dois problemas: o primeiro diz respeito à própria parcialidade com que conceitos são elaborados e o risco de manipulações conjeturais que disso resulta; o segundo, ao caráter industrioso, desenvolvimental da atividade e o quanto os conceitos, necessárias ferramentas, ambicionam neutralizá-lo.

$\mathrm{O}$ uso de certos conceitos e não de outros representa uma dada maneira de julgar, de decidir e de se engajar. A parcialidade natural com que são feitas as escolhas conceituais projeta os próprios epistemólogos para o campo das perplexidades: "Nada de reflexão epistemológica sem perplexidade por princípio sobre o que Kant chamava nossa faculdade de conceitos" (Schwartz, 1996, p. 141).

Na análise do trabalho, é preciso, portanto, precaução com a produção de conceitos: é preciso cuidado para não se cair na naturalização mecanicista dos fenômenos, para não desconhecer o conceito em sua dinâmica de possibilidades de valor e para não ceder às pressões no sentido de categorizar situações de maneira a dar respaldo às decisões unilaterais. Políticas são elaboradas para regular situações na base de palavras de ordem.

Alerta ainda o filósofo: o campo das atividades industriosas não é avaro em noções que misturam, insidiosamente, certos valores incorporados a ferramentas analíticas aparentemente neutras (Schwartz, 1997). Assim como 
não existem ferramentas neutras, também é preciso afastar de si qualquer vestígio de pensamento do trabalho como elemento neutro. Em casos como esse, a racionalização pode aparecer como um valor que estaria desvinculado de uma escolha parcial ou estratégica, mas "imperativa categoria diante da desordem, do desperdício, das resistências irracionais" (Schwartz, 1997, p. 5). Desse modo, desconsiderando as múltiplas razões engendradas pelas diversas lógicas que dinamizam o trabalho, escolhe-se 'a razão' falsamente suposta sem concorrência possível. Por isso, também a racionalização pela economia não se justifica. Da economia nem mesmo existe a possibilidade de advir 'uma' razão, mas a possibilidade de se declinar em versões bastante variáveis de 'algumas' razões. Sob que critérios escolher, então, uma delas, sem considerar seu estatuto de 'conceito-valor' da economia?

\section{Regime de produção de conhecimento}

Vários analistas do trabalho (Faïta, 2003; Schwartz, 2010b; Clot, 2010) estão de acordo com a premissa de que seu estudo obriga a articulação de competências. Na ótica de Schwartz, só se pode tocar a 'organização viva do trabalho' em colaboração: ergonomistas, linguistas, psicólogos, sociólogos, cada um deles necessita dos demais.

O estudo da linguagem, por exemplo, é fundamental para se compreender o trabalho. A presença do linguista no cenário da situação de trabalho é necessária. Em se tratando de uma organização viva de trabalho, há sempre formas de interação, de troca e de comunicação bastante variáveis. Faz-se necessária a sensibilidade para a linguagem.

Essa importância também estende-se, porém, a outras competências: por exemplo, o ergonomista sabe que é necessário extrair como informação a direção do olhar, os deslocamentos; o economista interessa-se pelas lógicas e pelos extratos econômicos de mercado; o psicólogo visa a transformar as situações de trabalho a fim de construir seus instrumentos de ação clínica.

Entretanto, se cada um extrai a dimensão que lhe diz respeito, o estudo pode ser aceito pela disciplina a que se liga. Porém, sob o ponto de vista dos profissionais, não pode ser validado. Afinal, eles vivem o conjunto, a articulação de todas essas dimensões, que, para eles, fazem parte de um conjunto. O trabalho como atividade coletiva não se deixa apreender por uma única disciplina.

É justamente o conceito de atividade que torna possível essa transitação, essa colaboração entre disciplinas. De acordo com Schwartz (2000), é o conceito de atividade que impõe a cada disciplina pensar em sua história interna, o que permite integrar a sua conceitualização às ideias fundamentais da atividade. 


\section{Interventor-ergologista}

Não se pode tomar decisões a priori sobre o tipo de alquimia que se vai realizar em cada movimento quando se propõe a estudar o trabalho. Segundo a perspectiva ergológica, os pesquisadores, de início, ligam-se em uma alquimia indefinida e opaca, o epistêmico e o 'transformativo', o desejo do conhecimento e as escolhas de engajamentos sobre os valores do mundo com que se confrontam (Schwartz, 1997).

Dois pressupostos de base orientam uma ação ergológica. O primeiro considera que a produção de conhecimento nas e sobre as situações de trabalho não pode tomar os trabalhadores como informantes. Eles são aqueles que possuem e vivem a experiência do trabalho. São eles que sentem calor, se irritam e têm prazer no trabalho que estão fazendo.

A metáfora do tear, elaborada pelo ergonomista francês François Daniellou, representa uma maneira interessante de ilustrar essa natureza complexa:

Em sua atividade laboral, homens ou mulheres tecem. Do lado da trama, os fios os ligam a um processo técnico, a propriedades da matéria, a ferramentas ou a clientes, a políticas econômicas - elaboradas eventualmente em outro continente --, a regras formais, ao controle de outras pessoas... Do lado da corrente (curtume), ei-los ligados a sua própria história, a seu corpo que aprende e envelhece; a uma multiplicidade de experiências de trabalho e de vida; a vários grupos sociais que lhes ofereceram saberes, valores e regras com as quais eles compõem dia após dia; a seus próximos também, fontes de energia e de preocupação; a projetos, desejos, angústias, sonhos... (Daniellou, 1996, p. 1, tradução nossa).

As disciplinas científicas, registra ainda Daniellou (1996), seguem, cada uma, seu próprio fio nesse tear, estruturando seus métodos e seus conceitos. Existe lugar nessa 'malha' para aquele que visa a compreender para transformar? Questiona-se o autor, fazendo alusão ao título do clássico livro em ergonomia de Guérin e colaboradores (2001).

A preocupação de Daniellou (1996) é amostra do quanto o estatuto epistemológico, no caso da ergonomia e das práticas ergonômicas em toda a sua variedade, é fonte de salutar, se não constante, processo de questionamento. Se, por um lado, o ergonomista dispõe de um conjunto de teorias e de modelos científicos para ajudar a esclarecer os fenômenos que encontra nas situações localmente estudadas, por outro, esse conjunto não pode facilmente constituir um bloco de conhecimentos voltados para a ação transformadora. A prática ergonômica, nesse sentido, impõe um trabalho que faça emergirem, aponta Daniellou (1996, p. 3, tradução nossa), “outras maneiras de ver, de dizer, de descrever, de modalizar". Cada ação ergonômica, portanto, longe de ser uma aplicação de métodos e, simultaneamente, de negar 
seu patrimônio epistêmico, desdobra-se em busca metodológica que não se esgota na análise ergonômica do trabalho.

No projeto de intervenção, é fundamental instituir espaços dialógicos com trabalhadores e pesquisadores, estabelecer algumas fronteiras de uma comunidade dialógica com um determinado fim: colocar o trabalho em discussão, colocar o trabalho 'em patrimônio'. Exemplos de constituição desses espaços se encontram no conhecimento sobre a existência de regras de ofício (Cru, 1995), de fatores de reconhecimento de si e de si pelos outros (Dejours, 1995), de estratégias defensivas (Dejours, 1987), dos usos que o trabalhador faz de si mesmo e de si por/pelo outro (Schwartz, 2009a).

O segundo pressuposto, bastante reivindicado nas pesquisas do linguista Daniel Faïta (2003), entende que a transformação da situação de trabalho não funciona se delegada a um especialista externo. A função do especialista é a de usar seu saber para fornecer meios e instrumentos de ação aos trabalhadores. Só eles e elas são capazes de produzir transformação. Os estudos de Faïta, desenvolvidos principalmente sobre a situacão de trabalho dos condutores de trem da companhia francesa SNCF, evidenciaram aquilo que Oddone, Re e Briante (1981) verificaram em análise realizada no final da década de 1960: o primado da 'não-delegação' a terceiros da responsabilidade de solução para problemas vividos coletivamente no trabalho. Nesse quadro, ganha continente nossa ação ergológica em resposta à demanda da direção do HU da UFRJ.

\section{Gestão do trabalho em serviços}

Schwartz (2009a) afirma que todo trabalho envolve dramáticas do uso de si, já que tanto existe a presença de normas heterodeterminadas como de renormatizações realizadas pelos próprios trabalhadores. Ele alerta que, ao falar de dramática, não se refere a um sofrimento, embora ele possa existir, mas ao fato de que sempre algo acontece no 'encontro de encontros' que é o trabalho, produzindo histórias. O planejamento é algo fundamental na gestão do trabalho e um dado importante na história da humanidade é essa capacidade de antecipação já apreciada por Marx (1985), a qual estudos de neurofisiologia recentes como o de Berthoz (apud Schwartz, 2000) vão fundamentar ainda mais ao afirmar que o cérebro não apenas reproduz a realidade, mas a emula. Schwartz (2009a) comenta como foi importante a construção do conceito de normas antecedentes para dar conta não apenas das normas que eram construídas pela prescrição dos chefes e gerentes, mas também das normas que eram construídas pelos próprios trabalhadores e que serviam de patrimônio para as gerações seguintes. Portanto, a ousadia dos humanos de desenhar o futuro é uma potência importante para a criação de seus meios de vida e de trabalho e um elemento fundamental do 
processo gestionário, já que possibilita que as criações provenientes das renormatizações não se percam na história, evitando-se a necessidade de sempre inventar a roda.

Porém, como o trabalho envolve necessariamente uma dimensão de 'encontros de encontros', onde a variabilidade técnica e humana está sempre presente e as normas antecedentes não conseguem dar conta dos novos desafios que surgem no presente, cada trabalhador é, ao mesmo tempo, convocado e convoca-se a lidar com o vazio de normas (Schwartz, 2009a) que surge devido aos imprevistos, tendo de criar novas normas para trabalhar, fazendo uso de si por si. Por isso que trabalhar é sempre gerir, e uma consequência imediata dessa perspectiva é a crítica de que só alguns trabalhadores da saúde seriam gestores (chefes, diretores, secretários e ministros de Estado). Todos os trabalhadores da saúde são gestores, já que todos criam normas para conseguir eficácia, e se essa gestão da variabilidade, através da renormatização não fosse realizada cotidianamente, a situação dos serviços de saúde pública estaria ainda pior, pois é exatamente essa atividade dos trabalhadores da saúde pública que explica como ainda pessoas são curadas apesar das condições de trabalho degradadas que se encontram nesses serviços. Assim, uma primeira tomada de posição seria não mais utilizar as palavras gestão ou gestor quando se tratasse do trabalho de um chefe ou diretor, mas as palavras gerenciamento e gerente. O que não implica uma desvalorização desses lugares já que, como diz Schwartz (2004, 2010a), é um grande desafio para um gerente assumir que já existem gestões e que se deve fazer a gestão das gestões, e não cair na sedução de adotar a "via mais simples, a de gerir de uma forma autoritária, com base no organograma, na prescrição, enquanto que não é a isto que se deve a eficácia de um coletivo" (Schwartz, 2010a, p. 163).

A atividade envolve sempre um debate de normas já que, para fazer face ao vazio de normas, deve-se criar novas normas para trabalhar. Nesse sentido, há escolhas muitas vezes radicais: ou você faz de uma maneira ou não faz. Assim, a eficácia não é neutra, mas construída a partir desse debate de normas, dessas escolhas que têm grande consequência na vida no trabalho. Schwartz (2009a) procura enfatizar que não se trata apenas de contornar ou transgredir normas já existentes, embora isso muitas vezes seja necessário. Ele salienta que, em certos momentos, a situação que surge no trabalho é tão singular que produz um vazio de normas e, portanto, não se trata de transgredir uma norma anterior, já que esta não existe, mas de criar uma nova norma. E essa criação de novas normas é que faz a possibilidade de construção de uma nova forma de trabalhar e de viver. É por isso que a atividade humana é vista por ele, mesmo nas situações mais difíceis como a do trabalho taylorista, como prenhe de reservas de alternativas (Schwartz, 2009b) para a construção de um novo modo de trabalhar e de viver juntos. 
Além disso, esse debate de normas acontece intimamente emaranhado com um mundo de valores. Há sempre uma relação com os valores pelos quais se escolhe uma norma para trabalhar e não outra. E isso é extremamente complexo, porque se, no caso das normas, tem-se muitas vezes uma oposição entre elas, no caso dos valores, pode-se contemplar valores diferentes em uma mesma escolha. Schwartz (2004) diferencia os valores mercantis, valores dimensionados, dos valores sem dimensão, como saúde, educação, liberdade e justiça, que deveriam ser dimensionados na história concreta, seja pelas instâncias que constroem as políticas de governo, seja pelas atividades concretas dos trabalhadores no cotidiano profissional. Aqui, surge uma armadilha dos processos de gerenciamento: como é difícil fazer esse dimensionamento, o caminho mais fácil tem sido o de adotar para esses valores o mesmo dimensionamento quantitativo utilizado nos valores mercantis, o que simplifica aparentemente o trabalho do gerente. Porém, ao se reduzir e mutilar a complexidade da atividade humana ao que pode ser quantificado, criam-se mais problemas insolúveis no campo da avaliação e do reconhecimento do trabalho, já que algumas atividades estratégicas para a eficácia do processo de trabalho não são avaliadas, nem reconhecidas. Assim, compreender melhor esses valores sem dimensão e como melhor trabalhar com eles no processo de gestão é uma das tarefas importantes para os pesquisadores.

Ora, mas se todos se envolvem nesse debate de normas imerso no mundo de valores, como construir uma assistência comum ao paciente? Por isso que Schwartz (2004) vai argumentar que existem negociações de eficácias para construir a gestão coletiva de trabalho e que a gestão do trabalho não é responsabilidade do indivíduo, mas das ECRPs. São elas que vão possibiltar a construção de renormatizações de forma coletiva, construindo negociações e debates de modo que as renormatizações não ocorram em um movimento individualista, em que cada um decide apenas por si, mas na sinergia da construção de um patrimônio histórico coletivo. Ele explica que são entidades porque não seguem as fronteiras do organograma, nem mesmo os limites de uma empresa; são coletivas porque compartilham debates, negociações, valores e a tarefa de realizar renormatizações e não apenas regulações; e, por fim, são relativamente pertinentes porque os limites de sua abrangência são variáveis, levando em conta o foco ou o problema situado que se precisa enfrentar. As fronteiras mudam segundo as pessoas e suas atividades. Assim, podemos tanto considerar uma entidade coletiva relativamente pertinente de uma forma ampla, como o movimento de luta pela reforma antimanicomial, ou uma menos abrangente, como profissionais da saúde de um serviço específico, usuários e seus parentes envolvidos em um determinado desafio comum da assistência em saúde. Trabalhadores podem atuar em uma mesma equipe segundo o organograma, mas efetivamente não 
se constituíram como entidade coletiva relativamente pertinente, enquanto os trabalhadores de serviços diferentes podem dialogar e negociar como prestar a melhor assistência a um usuário, ao lidar com uma situação inesperada. Schwartz (2010a) explica melhor o desafio dessas ECRPs de construir uma comunidade de valores:

Regras que supõem, para que as coisas funcionem uma comunidade de valores. A palavra talvez seja um pouco grande, mas sem essa comunidade de valores seria necessário negociar permanentemente as trocas, o que tomaria muito tempo.

Ora, vê-se que na maior parte dos casos, tudo corre bem. Existe algo da ordem dos valores comuns mais ou menos formalizados, que vai mais ou menos longe e que em certos momentos pode mostrar seus limites. Qualquer um poderia dizer: “Não, não é mais meu trabalho, isso não me interessa mais, eu tenho outras coisas a fazer". É por essa razão que é relativamente pertinente: é fluido, é frágil, muito frágil. Creio que é importante compreender como é frágil e como é um importante trabalho construir essas ECRPs, reconhecer sua construção, colaborar para sua construção e promover - eu diria - a relativa estabilidade dessa construção. Relativa porque os ambientes técnicos, as mudanças não param de modificá-las permanentemente (Schwartz, 2010a, p. 163).

Passaremos a seguir a trazer alguns exemplos de situações extraídas da análise ergonômica do trabalho efetivada nos serviços no hospital pesquisado.

\section{A gestão do trabalho e os valores sem dimensão: diversidade de situações}

Além da atividade dos recepcionistas do guichê de atendimento de marcar e de registrar exames, a análise ergonômica trouxe à tona a gestão de fluxo de pacientes como atividade-chave para lhes garantir a realização do exame. Regular e prever problemas relativos ao tempo de espera dos pacientes é núcleo central de investimentos de si no trabalho. Pautada como rotina pela ordem de chegada ou pela menção de urgência carimbada no pedido de exame, a gestão de fluxo de pacientes segue concomitantemente uma ordem própria, baseada em valores sem dimensão (Schwartz, 2009b), ou seja, valores que, ligados à própria história dos sujeitos, orientam suas ações.

A atividade precisa contar com uma declinação de valores por conta do risco de se caracterizar uma hiperindividualização que isola o trabalhador, deixando em suspenso a atividade desejada. O trabalho dos recepcionistas precisa contar com a participação dos técnicos e dos residentes, pois são estes que procedem aos exames. Sua tarefa se reorienta para a negociação com eles a respeito de eventual priorização do atendimento de determinado paciente.

Um recepcionista negocia fazer passar primeiro as crianças porque diz que observa que seu comportamento vai evoluindo para a impaciência, já 
que começa "a ficar com fome e cansada". Fazer a gestão dessas prioridades convoca a tessitura de uma gestão coletiva que coloca em relação a atividade dos recepcionistas e a dos técnicos e residentes que realizam os exames.

No mesmo serviço de marcação, um paciente vem para realizar exames de raios $\mathrm{X}$ da cabeça e das mãos e, no diálogo de atendimento, o recepcionista depreende com o paciente que este passara por quatro horas de hemodiálise naquele mesmo dia. Ele deixa seu posto e, entre outras ações, negocia a priorização daquele paciente com os dois técnicos responsáveis naquele dia pelos raios $\mathrm{X}$ de crânio e de mãos.

Assim, a gestão de fluxo de pacientes funciona na base de certa ordem social, da qual participam recepcionistas, técnicos e residentes. O recepcionista constrói junto com as equipes de serviço de ECRPs que renormatizam o fluxo de pacientes de acordo com alguns valores partilhados. Mas como dimensionar o valor saúde, a boa prestação de serviço naquela situação? Para operacionalizar concretamente esses valores, esse coletivo muitas vezes necessita exercitar, colocar o trabalho na clínica, ou seja, colocar o trabalho no foco de análise a fim de ampliar as possibilidades de ação.

Segundo um recepcionista, sua forma de selecionar e regular a passagem dos pacientes não funciona com as equipes de plantão de dois dos dias da semana. Com esses, diz ele, "eu não tenho chegada". O que isso significa? No futebol, não ter chegada é não conseguir aproximar-se da grande área, ficando o jogador sem possibilidade de visar ao gol. Para se alcançar essa "chegada", um jogador precisa do passe, da assistência dos outros jogadores, da jogada em suas diversas nuances para que possa haver possibilidade de gol. Esse gol para o recepcionista implica a possibilidade de atualizar, na atividade, uma orientação nova para o serviço, orientação que, 'para funcionar', deve ao mesmo tempo fazer parte de formas preexistentes, situadas na memória coletiva, disponíveis para o coletivo (Clot e Faïta, 2000). Com as equipes de terça e quinta-feira, essas formas não combinam, mas com as dos outros dias da semana, aparentemente, sim. Colocar o problema em discussão, promover o debate de valores e depreender formas de ECRPs delinear traços sobre aquilo que os recepcionistas colocam no centro das relações de serviço que constroem com os pacientes; entre outras tarefas, convoca o interventor-ergologista em seu trabalho em conjunto de ampliar o leque de critérios comuns, através dos quais possíveis mudanças na ordem cotidiana são legitimadas.

No entanto, essa negociação de eficácias é complexa porque os mesmos valores podem ser operacionalizados por normas diferentes e é por isso que muitas vezes a discordância aparece como parte construtiva do coletivo, sendo necessário apenas que haja a possibilidade de debater essas dissonâncias e produzir novos pactos e acordos. A dimensão coletiva do trabalho se expressa exatamente por esses debates, controvérsias, e é por isso que é 
crucial a comunicação, a cooperação e a existência de um espaço público de discussão (Dejours, 1993) para a gestão do trabalho. O que Schwartz (2009b, 2010a, 2010b) reforça é o papel dos valores nesse processo de construção do coletivo que ultrapassa os limites dos serviços, já que fazem parte da história de um ofício, de uma sociedade. Schwartz (2009b) enfatiza que se deve produzir historicamente a declinação de um mundo de valores, colocando em ordem, hierarquizando e organizando a sua concretude na vida social. Ele explica que:

há uma declinação, forçosamente, dos valores nas normas antecedentes. Mas ao mesmo tempo em razão do impossível e do invivível, porque é necessário viver, e que este viver deve operar em uma situação sempre recolocada em história, nossa relação com o mundo de valores é sempre ligada à nossa própria história, parte protagonista da história coletiva. A declinação desse mundo de valores é, muito profundamente, uma declinação sempre topologizada ou localizada por cada um na e pela situação (Schwartz, 2009b, p. 75, tradução nossa).

Outro exemplo que mostra a tessitura da gestão coletiva do trabalho no hospital é a relação desse serviço de exames com os serviços de internação cirúrgicos e clínicos. A análise do trabalho realizado em uma enfermaria de neurocirurgia vai salientar como os cirurgiões ressaltam a necessidade de um relacionamento com as pessoas da marcação de exames de imagens que permita reconfigurar os protocolos de marcação a partir da singularidade da situação dos pacientes. Um residente em neurocirurgia diz que uma das coisas mais importantes que desenvolveu depois de quatro anos de experiência naquele hospital foi o conhecimento de diferentes funcionários de cujo trabalho dependia e como, no início, não conseguia marcar mais cedo os exames de imagens, mas depois foi conseguindo argumentar, se tornando um interlocutor confiável, ponderando a situação do paciente e a gravidade do caso. Ele ressaltou também como - antes da chegada dos laudos escritos de exames do laboratório de patologia clínica na enfermaria - era fundamental uma conversa ao telefone com os funcionários do laboratório para saber do laudo oralmente, com vistas a providenciar mais rapidamente um antibiótico para combater uma infecção.

No mesmo serviço, um paciente portador de aneurisma cerebral precisou fazer uma angiografia, mas o aparelho do hospital não estava realizando imagens satisfatórias para traçar o diagnóstico preciso da região e preparar a cirurgia. Então, médicos e assistentes sociais desse hospital entraram em contato com profissionais de um serviço externo para que o usuário pudesse ser transportado até lá para fazer esse exame de imagem e depois retornar imediatamente com a devida segurança, já com o laudo pronto. Desse modo, percebia-se a construção de uma coletividade que envolvia 
profissionais de organizações diferentes para prestar assistência a um paciente de um dos serviços.

Entretanto, uma das críticas que alguns profissionais de enfermagem colocavam é que o espaço para o trabalho coletivo entre funcionários de equipes diferentes não era suficiente. Uma enfermeira que já tinha vivido uma situação onde a colaboração entre médicos e enfermeiros era mais estreita (no serviço para pacientes com Aids) afirmava sentir falta naquele serviço cirúrgico de uma colaboração mais próxima. Contudo, outra enfermeira e os médicos não tinham a mesma opinião. Salientavam que consideravam suficiente a participação da enfermeira-chefe nos rounds das enfermarias e na discussão de algumas providências.

Isso mostra que é muito difícil essa arquitetura coletiva, já que envolve expectativas diferentes do que é o viver e trabalhar juntos, enfrentar os desnivelamentos provocados na história das profissões em saúde e assumir a postura de, em vez de escondê-los, procurar construir estratégias e esforços para buscar reconhecer a igualdade de todos os seres humanos na capacidade de produzir normas nas suas atividades fundamentais para a eficácia, não sendo monopólio de qualquer indivíduo ou categoria profissional designar e arbitrar o que deve ser a eficácia de um serviço (Schwartz, 2010). Scherer, Pires e Schwartz (2009) vão descrever bem o cenário de dificuldades apresentadas ao trabalho coletivo no hospital:

O trabalho em saúde é marcado pela história das profissões que obtiveram uma definição de seu domínio de competências e atos próprios que pesam sobre a divisão do trabalho e sobre a fronteira entre os grupos.

A complexidade das formas de organização do trabalho coletivo introduzidas pela produção capitalista e suas mudanças recentes, bem como o paradigma positivista e a hegemonia da biomedicina têm influenciado o trabalho em saúde. A fragmentação de atividades dentro de campos profissionais e a influência da gerência científica nos serviços têm resultado em mudanças relacionadas ao controle sobre o processo de trabalho e a autonomia, característicos das profissões (Scherer, Pires e Schwartz, 2009, p. 723).

Um outro exemplo, presenciado na pesquisa em uma enfermaria de neurocirurgia, foi quando uma atendente de enfermagem, que tinha a função de organização e limpeza dos leitos e dos materiais usados para as necessidades fisiológicas dos pacientes, procurou a enfermeira-chefe do setor para lhe falar a respeito de um paciente que havia passado por uma neurocirurgia e tinha voltado do CTI para a enfermaria. Como ele ainda estava confuso e desorientado, se mexendo muito, ela quis colocar uma grade no leito para impedir uma possível queda, mas um médico disse que não havia necessidade. A enfermeira-chefe verificou o prontuário do paciente e leu 
uma comunicação da enfermagem do CTI alertando que o paciente ainda não estava totalmente orientado. Então, ela afirmou para a atendente que quem toma decisões a esse respeito é a enfermagem e disse para a mesma que ela poderia colocar a grade.

Percebemos nesse exemplo as dificuldades e potencialidades das relações coletivas de trabalho na enfermaria. A dificuldade da atendente de resolver diretamente com o médico a divergência de normas, o que a leva a buscar alianças com a enfermeira-chefe para fazer valer o seu posicionamento sobre qual é o gesto mais eficaz a ser realizado naquele momento, mas também a potencialidade presente no fato de a trabalhadora não desistir do seu ponto de vista, mesmo tendo a discordância de alguém com um saber e um poder mais reconhecido socialmente. Outra decisão que ela poderia ter tomado seria a de simplesmente não colocar as grades e deixar que a norma daquele médico prevalecesse. Por que ela insistiu e procurou a chefe de enfermagem para buscar apoio para a sua posição, para a sua norma, que era colocar a grade?

Por intermédio de Schwartz (2009b, 2010a), percebemos que renormatizar é um movimento de vida e saúde e que os valores dão sentido à existência e ao trabalho, e são esses valores que vão constituindo a atendente como uma profissional da saúde, importante como os outros para o cuidado do paciente, cuja contribuição singular é imprescindível para a assistência ao usuário. Assim, é no dimensionamento concreto do que deveria ser o 'valor saúde pública' que se constrói a materialização de uma grade no leito. Esse instrumento, em outra situação, pode ser um desserviço para a autonomia e mobilidade do usuário, mas, naquela situação específica, protegeu sua vida. As ECRPs são o lugar da construção de modos de viver juntos, associados aos valores. O importante na situação é que a atendente pôde tomar uma decisão com respaldo coletivo e não apenas individual, baseada em valores comuns da enfermagem sobre a importância do cuidado para a saúde.

\section{Considerações finais}

O trabalho em saúde é um lugar onde diferentes ECRPs se tecem por fios de normas que se ligam a valores: mercantis (mensuráveis) e os do bem comum (sem dimensão). No caso dos recepcionistas que fazem a gestão do tempo de espera dos pacientes, eles devem corresponder simultaneamente a normas antecedentes gerais, relativas aos procedimentos e à organização do trabalho. Mas devem também corresponder ao tratamento singular de situações específicas dos pacientes que colocam em debate valores sem escala de medida, valores sem dimensão. Esse debate convoca o trabalho coletivo (Athayde, 1988, 1996), mas não de qualquer coletivo, e sim das ECRPs que, em síntese, 
dão forma às escolhas de valores e ao que Schwartz propõe como o 'corposi'. Essas configurações coletivas relativamente pertinentes manifestam uma subjetividade que, transcendendo o individual, justifica colocar o trabalho e essa 'gestão do corpo-si' na mira do olhar e da ação transformadora. O corpo-si toma forma nas ações que envolvem o diálogo com técnicos e residentes na direção de priorizar o atendimento de determinado paciente. No caso do serviço de internações em neurocirurgia, chega-se a formar coletivos com serviços de outros hospitais.

Desse modo, percebemos que várias ECRPs vão se constituindo nos serviços de saúde pública, construindo novas normas para o trabalho baseadas em valores (seja os do bem comum, seja os mercantis). Se um paciente cai do leito e atrasa sua recuperação, ou se devido a uma demora no seu diagnóstico atrasa sua cirurgia ou sua recuperação pós-operatória, aumenta o seu tempo de permanência no hospital público, trazendo prejuízos para o frágil orçamento hospitalar. Portanto, todas essas regulações citadas com certeza tinham ancoragem em valores mercantis, dimensionados. Porém, ao mesmo tempo, elas produzem efeitos positivos na saúde dos pacientes, um valor do bem comum, que une usuários e diferentes profissionais desse hospital e de outros serviços fora do hospital (Muniz, 2000). Assim, a perspectiva ergológica procura combater dicotomias, já que não se trata de demonizar os valores mercantis, nem de se furtar da responsabilidade e do desafio de dimensionar e declinar os valores do bem comum, mas procurar, com o auxílio dos protagonistas da atividade, avaliar a eficácia do trabalho a partir da complexidade de sua atividade, no processo de seu desenvolvimento, e não apenas através de mensurações de seus resultados aparentes (Schwartz, 1992).

No entanto, essa negociação de eficácias é complexa porque os mesmos valores podem ser operacionalizados por normas diferentes e é por isso que, muitas vezes, a discordância é vivenciada de um modo que dificulta as possibilidades de ação, quando seria desejável que fosse uma força, uma riqueza do coletivo.

Por isso, torna-se necessário colocar esse trabalho na berlinda, criar espaços dialógicos, clínicos, capazes de pôr o problema em discussão, promover o debate de normas e valores e depreender formas de ECRPs. A fim de discutir o trabalho de serviços de saúde no Brasil, visamos a colocar 'a atividade em história' propondo um quadro específico do contexto sóciohistórico da intervenção. A história muda, mas a dinâmica das renormatizações, por sua vez, mantém-se como fiel característica da humanidade. Devese militar por fazer a gestão das gestões e não cair na sedução de adotar a “via mais simples, a de gerir de uma forma autoritária, com base no organograma, na prescrição, enquanto que não é a isto que se deve a eficácia de um coletivo" (Schwartz, 2010a, p. 163). 
Nessa direção, pela riqueza de ponderações que convoca, a perspectiva ergológica oferece um quadro bastante interessante em termos de ligar o acadêmico, o conceitual e o epistêmico aos patrimônios dessas ECRPs e as reservas de alternativas presentes nas suas atividades, o que consideramos como uma afirmação das reais possibilidades transformadoras das situações de trabalho em saúde.

\section{Notas}

1 Professora associada do Departamento de Processos Técnicos e Documentais da Universidade Federal do Estado do Rio de Janeiro (Unirio), Rio de Janeiro, Brasil. Pós-doutora em Psicologia do Trabalho pelo CNAM, Paris, França. <mbfranca@hotmail.com> Correspondência: Avenida São Sebastião, 105/304, CEP 22291-070, Rio de Janeiro, RJ, Brasil.

2 Professor associado do Departamento de Psicologia da Universidade Federal Fluminense (UFF), Niterói, Brasil. Pós-doutor em Psicologia Social do Trabalho e das Organizações pela Universidade do Estado do Rio de Janeiro (Uerj).<heldermuniz@uol.com.br>

3 Alain Gras (2001), antropólogo e sociólogo, oferece uma interessante discussão sobre o conceito-valor de 'avanço e progresso', discutindo a hipótese de que a tecnologia é socialmente construída e de que é vã a procura de um porvir autônomo de técnicas, orientado apenas pela eficácia.

\section{Referências}

ANTUNES, Ricardo. Dimensão da precarização estrutural do trabalho. In: DRUCK, Graça; FRANCO, Tânia. (Orgs.). A perda da razão social do trabalho: terceirização e precarização. São Paulo: Boitempo, 2007. p. 13-22.

ATHAYDE, Milton. Processo produtivo, espaço educativo: um campo de lutas. Dissertação (Mestrado em Educação) - João Pessoa: Programa de Pós-Graduação em Educação, Universidade Federal da Paraíba, 1988.

Gestão de coletivos de trabalho e modernidade. Tese (Doutorado em Engenharia de Produção/Gerência da Produção/Ergonomia) - Rio de Janeiro: Coppe - Instituto Alberto Luiz Coimbra de Pós-Graduação e Pesquisa de Engenharia, Universidade Federal do Rio de Janeiro, 1996.

CLOT, Yves. Trabalho e poder de agir. Belo Horizonte: Fabrefactum, 2010.

CLOT, Yves; FAÏTA, Daniel. Genres et styles en analyse du travail. Concepts et méthodes. Travailler, Revue Internationale de Psychopathologie et de Psychodynamique du Travail, n. 4, p. 7-42, 2000. 
CRU, Damien. Règles de Métier, Langue de Métier: dimension symbolique au travail et démarche participative de prévention. Mémoire EPHE. Paris, 1995.

DANIELLOU, François. Questions épistémologiques autour de l'érgonomie. In: . (Dir.). L'Ergonomie en Quête de ses Principes. Toulouse: Octares, 1996. p. 1-18.

DEJOURS, Christophe. Souffrance et plaisir au travail: l'approche par la psychopathologie du travail. In: __ (Org.). Plaisir et Souffrance dans le Travail. Paris: AOCIP/CNRS, 1987.

. Inteligência operária e organização do trabalho: a propósito do modelo japonês de produção. In: HIRATA, Helena. (Org.). Sobre o modelo japonês: automatização, novas formas de organização e de relações de trabalho. São Paulo: Edusp, 1993. p. 280-309.

Analyse psychodynamique des situations de travail et sociologie du langage. In: BOUTET, Josiane. (Dir.). Paroles au Travail. Paris: L'Harmattan, 1995. p. 181-224.

FAÏTA, Daniel. Análise dialógica da atividade profissional. Rio de Janeiro: Imprinta, 2003.

FRANÇA, Maristela B. Uma comunidade dialógica de pesquisa: atividade e discurso em guichê de atendimento hospitalar. Tese (Doutorado em em Linguística Aplicada e Estudos da Linguagem) - São Paulo: Pontifícia Universidade Católica, 2002.

GOMES, Rafael da S. O trabalho no Programa Saúde da Familia do ponto de vista da atividade: a potência, os dilemas e os riscos de ser responsável pela transformação do modelo assistencial. Tese (Doutorado em Saúde Pública) - Rio de Janeiro: Escola Nacional de Saúde Pública, Fundação Oswaldo Cruz, 2009.

GRAS, Alain. L'ilusion de la faculté technique. L'Ecologiste, v. 2, n. 5, p. 26-33, 2001.

GUÉRIN, François et al. Compreender o trabalho para transformá-lo: a prática da ergonomia. São Paulo: Edgar Blücher, 2001.
HENNINGTON, Élida A. Gestão dos processos de trabalho e humanização em saúde: reflexões a partir da ergologia. Revista de Saúde Pública, São Paulo, v. 42, n. 3, p. 555561, jun. 2008

JOAZEIRO, Edna M. G. Formação no trabalho do estágio supervisionado em Serviço Social na saúde pública: desafios. Dissertação (Mestrado em Educação) - Campinas: Faculdade de Educação, Universidade Estadual de Campinas, 2002.

Serviço social e supervisão de estágio: saberes, formação e temporalidades. Tese (Doutorado em Educação) - Campinas: Faculdade de Educação, Universidade Estadual de Campinas, 2008.

MARX, Karl. O capital. Volume I, tomo 1. São Paulo: Nova Cultural, 1985.

MASSON, Letícia P. A dimensão relacional do trabalho de auxiliares de enfermagem de unidade neonatal: uma análise do ponto de vista da atividade. Dissertação (Mestrado em Saúde Pública) - Rio de Janeiro: Escola Nacional de Saúde Pública, Fundação Oswaldo Cruz, 2007.

MONTEIRO DA SILVA, Nair. Setor de emergência: modos de trabalhar nas interfaces de um cotidiano hospitalar. Dissertação (Mestrado em Psicologia) - Niterói: Universidade Federal Fluminense, 2008

MUNIZ, Hélder. P. A gestão do tempo de permanência do paciente de neurocirurgia no Hospital Universitário Clementino Fraga Filho. Tese (Doutorado em Engenharia de Produção) - Rio de Janeiro: Coppe - Instituto Alberto Luiz Coimbra de Pós-Graduação e Pesquisa de Engenharia, Universidade Federal do Rio de Janeiro, 2000.

ODDONE, Ivar; RE, Alessandra; BRIANTE, Gianni. Redécouvrir l'Experience Ouvrière. Vers une autre psychologie du travail? Paris: Messidor/Éditions Sociales, 1981.

RAMMINGER, Tatiana. 'Cada Caps é um Caps': a importância dos saberes investidos 
na atividade para o desenvolvimento do trabalho em saúde mental. Tese (Doutorado em Saúde Pública) - Rio de Janeiro: Escola Nacional de Saúde Pública Sérgio Arouca, Fundação Oswaldo Cruz, 2009.

SANTORUM, Kátia. Pelas fendas do trabalho vivo: textos, contextos e atos na atividade de vigilância em saúde do trabalhador. Tese (Doutorado em Saúde Pública) - Rio de Janeiro: Escola Nacional de Saúde Pública Sérgio Arouca, Fundação Oswaldo Cruz, 2006.

SCHERER, Magda D. A. O trabalho da equipe de saúde da família: possibilidades de construção da interdisciplinaridade. Tese (Doutorado em Enfermagem) - Florianópolis: Programa de Pós-Graduação em Enfermagem, Universidade Federal de Santa Catarina, 2006.

SCHERER, Magda D. A; PIRES, Denise; SCHWARTZ, Yves. Trabalho coletivo: um desafio para a gestão em saúde. Revista de Saúde Pública, São Paulo, v. 43, n. 4, p. 721-725, 2009.

SCHWARTZ, Yves. Avances et limites de la conceptualisation économiste. In: DÉPARTEMENT D'ERGOLOGIE. (Org.). L'Évaluation Économique a l'Épreuve des Services: l'activité entre efficacité et efficience. Aix-en-Provence: Université de Provence, 1992. p. 69-82

Ergonomie, philosophie et exterritorialité. In: DANIELLOU, François (Dir.) L'Ergonomie en Quête de ses Principes. Toulouse: Octarès, 1996. p. 141-182.

. Le Paradigme Ergologique ou un Métier de Philosophe. Toulouse: Octarès, 2000.

. Travail et ergologie. In: (Org.). Reconnaissances $d u$ Travail: pour une approche ergologique. Paris: PUF, 1997. p. 1-37.

Trabalho e gestão: níveis, critérios, instâncias. In: FIGUEIREDO, M. et al. (Orgs.). Labirintos do trabalho: interrogações e olhares sobre o trabalho vivo. Rio de Janeiro: DP\&A, 2004. p. 23-33.
Dialogue 1 - Trajectoires et usages de soi. In:____ _ DURRIVE, Louis. (Orgs.). L'Activité en Dialogues: entretiens sur l'activité humaine (II). Toulouse: Octarès, 2009a. p. 9-33.

Dialogue 2 - Débat de normes, 'monde des valeurs' et engagement transformateur. In: .; DURRIVE, Louis (Org.) L'Activité en Dialogues: entretiens sur l'activité humaine (II). Toulouse: Octarès, 2009b. p. 35-99.

A dimensão coletiva do trabalho e as Entidades Coletivas Relativamente Pertinentes (ECRP). In: .; DURRIVE, Louis. (Orgs.). Trabalho e ergologia: conversas sobre atividade humana. 2. ed. Niterói: Eduff, 2010a. p. 149-164.

O homem, o mercado e a cidade. In: __ .; DURRIVE, Louis. (Orgs.). Trabalho e ergologia: conversas sobre atividade humana. 2. ed. Niterói: Eduff, 2010b. p. 247-273.

SILVA, Ana Cláudia B. A gestão de unidades básicas de saúde frente ao desafio da estratégia de saúde da família. Dissertação (Mestrado em Psicologia Social) - Rio de Janeiro: Programa de Pós-Graduação em Psicologia Social, Universidade do Estado do Rio de Janeiro, 2006.

SOUZA, Wladimir. F. Gestão em saúde, uma perspectiva ergológica: com quantos gestos se faz uma gestão. Tese (Doutorado em Psicologia Social) - Rio de Janeiro: Programa de Pós-Graduação em Psicologia Social, Universidade do Estado do Rio de Janeiro, 2009.

VIDAL, Mario C. Ergonomia e novas tecnologias: implantação e consolidação do Gente/Coppe. Relatorio final, 1997. Mimeografado.

VIDAL, Mario C. et al. Ação ergonômica com vistas à informatização do fluxo de exames complementares de diagnóstico e tratamento. Programa de Capacitação em Ergonomia Hospitalar: Projeto 1. Gente/PEP/Coppe/UFRJ 
e HUCCFF/UFRJ, Rio de Janeiro, 1997. Mimeografado.

VILLA, Eliana A. Pedagogia do cuidado: a relação de saberes e valores no trabalho do Programa Saúde da Família. Tese (Doutorado em Educação) - Belo Horizonte: Faculdade de Educação, Universidade Federal de Minas Gerais, 2008.

Recebido em 17/01/2011

Aprovado em 20/02/2011 